\title{
ASO Visual Abstract: Cutting Instruments to Cut Costs-A Simple Initiative with Breast Surgical OR Trays that Resulted in Substantial Savings
}

Jandie Schwartz, DO ${ }^{1}$, Lindsey Kirkpatrick, DO $^{1}$, Karalyn E. Hillebrecht, $\mathrm{MD}^{\mathbf{2}}$, Joanna S. Lee, MD ${ }^{1}$, Jennifer G. Steiman, MD ${ }^{1}$, Atilla Soran, MD ${ }^{1}$, Ronald R. Johnson, MD ${ }^{1}$, Priscilla F. McAuliffe, MD, PhD ${ }^{1}$, and Emilia J. Diego, MD ${ }^{1}$

${ }^{1}$ Section of Breast Surgery, Department of Surgery, University of Pittsburgh Medical Center Magee-Womens Hospital, Pittsburgh, PA; ${ }^{2}$ University of Pittsburgh Medical Center Mercy Hospital, Pittsburgh, PA

To decrease healthcare costs, the financial impact of a systematic reduction in the institutional instrument tray contents for breast procedures was evaluated (https://doi. org/10.1245/s10434-021-10496-y). Tray downsizing by $49 \%$ resulted in a hospital annualized savings of $\$ 287,802$ per year.

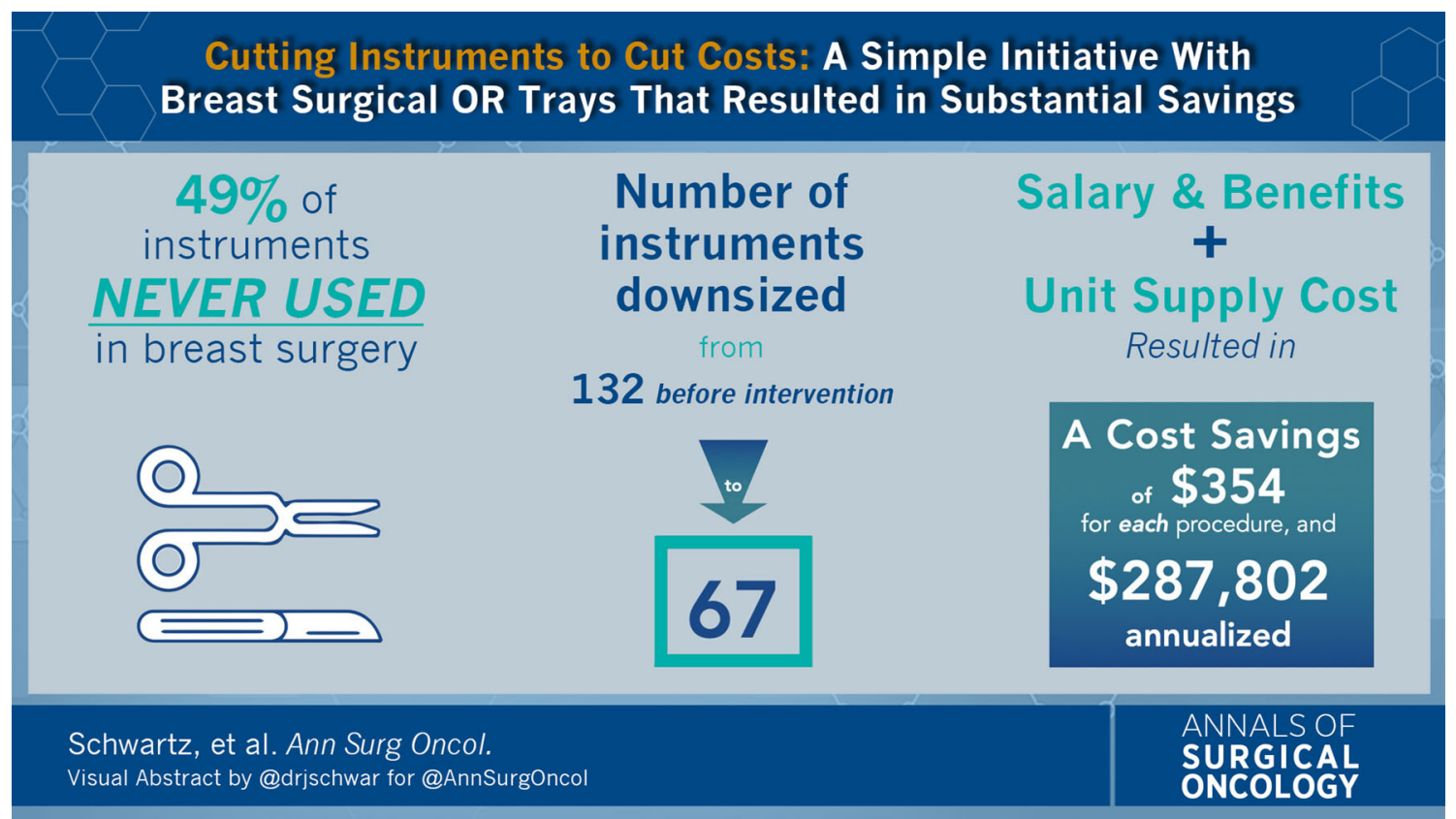

(C) Society of Surgical Oncology 2021

Publisher's Note Springer Nature remains neutral with regard to Published Online: 9 August 2021

E. J. Diego, MD

e-mail: diegoe@upmc.edu 